\title{
Calcium influx activates adenylyl cyclase 8 for sustained insulin secretion in rat pancreatic beta cells
}

\author{
Haiqiang Dou • Changhe Wang • Xi Wu • Lijun Yao • Xiaoyu Zhang • Sasa Teng • \\ Huadong Xu • Bin Liu • Qihui Wu • Quanfeng Zhang • Meiqin Hu • Yeshi Wang • \\ Li Wang • Yi Wu • Shujiang Shang • Xinjiang Kang • Lianghong Zheng • \\ Jin Zhang • Matthieu Raoux • Jochen Lang • Qing Li • Jing Su • Xiao Yu • \\ Liangyi Chen • Zhuan Zhou
}

Received: 16 June 2014 / Accepted: 8 October 2014 /Published online: 9 November 2014

(C) Springer-Verlag Berlin Heidelberg 2014

\begin{abstract}
Aims/hypothesis Insulin is a key metabolic regulator in health and diabetes. In pancreatic beta cells, insulin release is regulated by the major second messengers $\mathrm{Ca}^{2+}$ and cAMP: exocytosis is triggered by $\mathrm{Ca}^{2+}$ and mediated by the cAMP/protein kinase A (PKA) signalling pathway. However, the causal link between these two processes in primary beta cells remains undefined.
\end{abstract}

Haiqiang Dou and Changhe Wang contributed equally to this work.

Electronic supplementary material The online version of this article (doi:10.1007/s00125-014-3437-z) contains peer-reviewed but unedited supplementary material, which is available to authorised users.

H. Dou $\cdot$ C. Wang $\cdot$ X. Wu $\cdot$ L. Yao $\cdot$ X. Zhang $\cdot$ S. Teng $\cdot$ H. Xu $\cdot$ B. Liu $\cdot$ Q. Wu $\cdot$ Q. Zhang $\cdot$ M. Hu $\cdot$ Y. Wang $\cdot$ L. Wang $\cdot$ Y. Wu $\cdot$ S. Shang $\cdot$ X. Kang $\cdot$ L. Zheng $\cdot$ L. Chen $(\square) \cdot Z$. Zhou $(\square)$ Institute of Molecular Medicine, Peking University, 5 Yiheyuan Road, Beijing 100871, China

e-mail: lychen@pku.edu.cn

e-mail: zzhou@pku.edu.cn

H. Dou $\cdot$ C. Wang $\cdot$ X. Wu $\cdot$ L. Yao $\cdot$ X. Zhang $\cdot$ S. Teng $\cdot$ H. Xu $\cdot$ B. Liu $\cdot \mathrm{Q}$. Wu $\cdot$ Q. Zhang $\cdot \mathrm{M}$. Hu $\cdot \mathrm{Y}$. Wang $\cdot$ L. Wang $\cdot \mathrm{S}$. Shang

X. Kang $\cdot$ L. Zheng $\cdot$ Z. Zhou

State Key Laboratory of Biomembrane and Membrane

Biotechnology, Peking University, Beijing,

People's Republic of China

H. Dou $\cdot$ C. Wang $\cdot$ X. Wu $\cdot$ L. Yao $\cdot$ X. Zhang $\cdot$ S. Teng $\cdot$ H. Xu $\cdot$

B. Liu $\cdot$ Q. Wu $\cdot$ Q. Zhang $\cdot$ M. Hu $\cdot$ Y. Wang $\cdot$ L. Wang $\cdot$ Y. Wu

S. Shang $\cdot$ X. Kang $\cdot$ L. Zheng $\cdot$ L. Chen $\cdot$ Z. Zhou

Beijing Key Laboratory of Cardiometabolic Molecular Medicine,

Peking University, Beijing, People's Republic of China

H. Dou $\cdot$ C. Wang $\cdot$ X. Wu $\cdot$ L. Yao $\cdot$ X. Zhang $\cdot$ S. Teng $\cdot$ H. Xu $\cdot$ B. Liu $\cdot$ Q. Wu $\cdot$ Q. Zhang $\cdot$ M. Hu $\cdot$ Y. Wang $\cdot$ L. Wang $\cdot$ S. Shang

X. Kang $\cdot$ L. Zheng $\cdot$ Z. Zhou

PKU-IDG/McGovern Institute for Brain Research, Peking

University, Beijing, People's Republic of China
Methods Time-resolved confocal imaging of fluorescence resonance energy transfer signals was performed to visualise PKA activity, and combined membrane capacitance recordings were used to monitor insulin secretion from patchclamped rat beta cells.

Results Membrane depolarisation-induced $\mathrm{Ca}^{2+}$ influx caused an increase in cytosolic PKA activity via activating a $\mathrm{Ca}^{2+}$ sensitive adenylyl cyclase 8 (ADCY8) subpool. Glucose

H. Dou $\cdot$ C. Wang $\cdot$ X. Wu $\cdot$ L. Yao $\cdot$ X. Zhang $\cdot$ S. Teng $\cdot$ H. Xu $\cdot$ B. Liu $\cdot$ Q. Wu $\cdot$ Q. Zhang $\cdot$ M. Hu $\cdot$ Y. Wang $\cdot$ L. Wang $\cdot$ S. Shang $\cdot$ $\mathrm{X}$. Kang $\cdot$ L. Zheng $\cdot$ Z. Zhou

Peking-Tsinghua Centre for Life Sciences, Peking University, Beijing, People's Republic of China

\author{
J. Zhang \\ Department of Pharmacology and Molecular Sciences, \\ The Johns Hopkins University School of Medicine, \\ Baltimore, MD, USA
}

M. Raoux $\cdot$ J. Lang

Université de Bordeaux I Institut Européen de Chimie et Biologie UMR CNRS 5248, Bordeaux, France

Q. Li $\cdot$ J. Su X. Yu $(\square)$

Department of Physiology, Shandong University School of

Medicine, 44 Wenhua Xi Road, Jinan 250012,

People's Republic of China

e-mail: yuxiao@sdu.edu.cn 
stimulation triggered coupled $\mathrm{Ca}^{2+}$ oscillations and PKA activation. ADCY8 knockdown significantly reduced the level of depolarisation-evoked PKA activation and impaired replenishment of the readily releasable vesicle pool. Pharmacological inhibition of PKA by two inhibitors reduced depolarisation-induced PKA activation to a similar extent and reduced the capacity for sustained vesicle exocytosis and insulin release.

Conclusions/interpretation Our findings suggest that depolarisation-induced $\mathrm{Ca}^{2+}$ influx plays dual roles in regulating exocytosis in rat pancreatic beta cells by triggering vesicle fusion and replenishing the vesicle pool to support sustained insulin release. Therefore, $\mathrm{Ca}^{2+}$ influx may be important for glucose-stimulated insulin secretion.

Keywords Adenylyl cyclase $8 \cdot \mathrm{Ca}^{2+} \cdot$ Pancreatic beta cell $\cdot$ Protein kinase A $\cdot$ Vesicle pool

$\begin{array}{ll}\text { Abbreviations } \\ \Delta \mathrm{R} & \text { Normalised FRET ratio } \\ \mathrm{ADCY} & \text { Adenyl cyclase } \\ {\left[\mathrm{Ca}^{2+}\right]_{\mathrm{i}}} & \text { Intracellular free } \mathrm{Ca}^{2+} \text { concentration } \\ \text { cAMP } & \text { Cyclic AMP } \\ {[\mathrm{cAMP}]_{\mathrm{i}}} & \text { Intracellular free cyclic AMP concentration } \\ \mathrm{CFP} & \text { Cyan fluorescent protein } \\ \mathrm{C}_{\mathrm{m}} & \text { Membrane capacitance } \\ \text { DDA } & 2^{\prime}, 5^{\prime} \text {-dideoxyadenosine } \\ \text { EPAC2 } & \text { Exchange protein directly activated } \\ & \text { by cAMP 2 } \\ \text { FRET } & \text { Fluorescence resonance energy transfer } \\ \text { GLP-1 } & \text { Glucagon-like peptide1 } \\ \text { IBMX } & \text { 3-Isobutyl-1-methylxanthine } \\ \text { IRP } & \text { Immediately releasable pool } \\ \text { KD } & \text { Knockdown } \\ \text { PDE } & \text { Phosphodiesterase } \\ \text { PKA } & \text { Protein kinase A } \\ \text { RRP } & \text { Readily releasable pool } \\ \text { sh-ADCY8 } & \text { ADCY8 short hairpin RNA } \\ \text { sh-Ctr } & \text { Scrambled control short hairpin RNA } \\ \text { TEA } & \text { Tetraethylammonium chloride } \\ \text { YFP } & \text { Yellow fluorescent protein } \\ \text { VGCC } & \text { Voltage-gated Ca }{ }^{2+} \text { channel } \\ & \end{array}$

\section{Introduction}

Insulin regulates blood glucose metabolism and helps maintain energy homeostasis. Impaired insulin secretion leads to glucose intolerance and diabetes. In response to increased blood glucose, the cytosolic ATP/ADP ratio in pancreatic beta cells increases [1]. This change leads to the closure of $\mathrm{K}_{\mathrm{ATP}}$ channels, which depolarises the membrane, causing $\mathrm{Ca}^{2+}$ influx and subsequent exocytosis of insulin granules [2, 3]. Thus, elevated intracellular $\mathrm{Ca}^{2+}\left(\left[\mathrm{Ca}^{2+}\right]_{\mathrm{i}}\right)$ in pancreatic beta cells is known to be the major trigger for glucose-stimulated insulin secretion.

Cyclic AMP (cAMP) is another important second messenger that enhances vesicle fusion via both protein kinase A (PKA)-dependent and PKA-independent pathways, which are dependent on exchange protein directly activated by cAMP 2 (EPAC2) [4-6]. Endogenous incretin hormones, such as glucose-dependent insulinotropic polypeptide [7] and glucagon-like peptide1 (GLP-1) [8], act on membrane receptors to generate cytoplasmic cAMP and regulate insulin secretion. Glucose metabolism also triggers cytoplasmic cAMP elevation and oscillations in pancreatic beta cells, although the underlying mechanisms and the physiological significance of this process remain unclear [9-12].

Crosstalk between these key regulators of insulin secretion, the $\mathrm{Ca}^{2+}$ and cAMP signalling pathways, occurs within individual beta cells. Both $\mathrm{Ca}^{2+}$-activated and $\mathrm{Ca}^{2+}$-inhibited adenyl cyclase (ADCY) isoforms are expressed in insulinsecreting cells [13]. $\mathrm{Ca}^{2+}$-activated phosphodiesterase (PDE) has been proposed to mediate cAMP oscillations in clonal MIN6 cells $[14,15]$. Similarly, cAMP accumulation activates PKA, leading to phosphorylation of voltage-gated $\mathrm{Ca}^{2+}$ channels (VGCCs) on the plasma membrane $[16,17]$ and inositol 1,4,5-trisphosphate and ryanodine receptors on the endoplasmic membrane $[18,19]$. Owing to the complexity of these interactions, the temporal and causal relationships between the $\mathrm{Ca}^{2+}$ - and cAMP/PKA-mediated pathways in beta cells remain undefined [11, 13-15, 20, 21]. It is unclear whether and how glucose or depolarisation triggers activation of the cAMP/PKA pathway, and vice versa.

In the present study, we used a genetically encoded AKAR3 reporter [22] to monitor the real-time activity of PKA in primary beta cells using fluorescence resonance energy transfer (FRET). By combining membrane capacitance $\left(\mathrm{C}_{\mathrm{m}}\right)$ measurements with FRET imaging in individual beta cells, we showed that depolarisation-induced $\mathrm{Ca}^{2+}$ influx activates PKA via an adenylyl cyclase 8 (ADCY8) subpool and thus helps to replenish the readily releasable pool (RRP) of insulin granules during glucose stimulation.

\section{Methods}

Detailed materials and methods are available in the electronic supplementary materials (ESM Methods).

Cell culture and transfection Pancreatic islet beta cells from adult Wistar rats (150-250 g) were isolated and cultured as previously described [23]. Briefly, rats were killed by cervical dislocation and islets were obtained from the pancreas by collagenase P digestion. After short-term tissue culture 
(4-24 h) in RPMI 1640 medium, single beta cells were isolated by treating the islets with $0.025 \%$ trypsin (Invitrogen, Carlsbad, CA, USA). Transfection was conducted using the Neon $10 \mu \mathrm{l}$ transfection system MPK10096 (Invitrogen). Experiments were performed 24-72 h after transfection, or $>72 \mathrm{~h}$ for ADCY8 knockdown (KD).

Real-time FRET and $\mathrm{Ca}^{2+}$ imaging Live imaging of the AKAR3 fluorescent PKA reporter was performed using a Zeiss 710 inverted confocal microscope (Carl Zeiss, Oberkochen, Germany). AKAR3 was excited using a $405 \mathrm{~nm}$ laser, and a simultaneous two-channel mode was used for emission detection: one channel for cyan (466-489 nm) and the other for yellow $(519-535 \mathrm{~nm})$. The FRET ratio was calculated as $\mathrm{R}=\mathrm{F}_{\mathrm{YFP}} / \mathrm{F}_{\mathrm{CFP}}$, and normalised as $\Delta \mathrm{R}=\Delta \mathrm{R}^{\prime} / \mathrm{R}$, where $\Delta R^{\prime}$ is the absolute change in the FRET ratio, to take into account variation in the basal FRET ratio among different cells. For simultaneous imaging of $\left[\mathrm{Ca}^{2+}\right]_{\mathrm{i}}$ and FRET, cells were preloaded with $5 \mu \mathrm{mol} / \mathrm{l}$ Rhod-2 AM (Invitrogen) for $<10 \mathrm{~min}$, and the switched mode of frame-scan was used to alternately detect FRET and $\mathrm{Ca}^{2+}$ signals. $\mathrm{Ca}^{2+}$ signals were detected at $543 \mathrm{~nm}$ excitation and 560-620 nm emission. Images were acquired at $0.5 \mathrm{~Hz}$, and the temperature was maintained at $28-32^{\circ} \mathrm{C}$ using a TempModule S (Carl Zeiss). Control solutions and drugs were applied locally to individual cells during recording using a multichannel microperfusion system [24].

Electrophysiology and membrane capacitance recording Whole-cell and perforated whole-cell configurations were used as previously described [3, 25]; the latter configuration was used during imaging to avoid loss of fluorescence intensity resulting from protein leakage into the pipette. For H-89 inhibition experiments, cells were dialysed with a solution containing $15 \mu \mathrm{mol} / 1 \mathrm{H}-89$ for $>7 \mathrm{~min}$. Beta cells were characterised as healthy cells with a $\mathrm{C}_{\mathrm{m}}$ of $>4 \mathrm{pF}$ and no $\mathrm{Na}^{+}$ current [23]. The standard extracellular solution contained $118 \mathrm{mmol} / \mathrm{l} \mathrm{NaCl}, 20 \mathrm{mmol} / \mathrm{l}$ tetraethylammonium chloride (TEA), $5.6 \mathrm{mmol} / \mathrm{l} \mathrm{KCl}, 2.6 \mathrm{mmol} / 1 \mathrm{CaCl}_{2} \cdot 2 \mathrm{H}_{2} \mathrm{O}, 1.2 \mathrm{mmol} / \mathrm{l}$ $\mathrm{MgCl}_{2}, 5 \mathrm{mmol} / \mathrm{l} \mathrm{D}$-glucose and $5 \mathrm{mmol} / \mathrm{l} \mathrm{HEPES}$ at $\mathrm{pH}$ 7.4. The intracellular solution contained $152 \mathrm{mmol} / 1 \mathrm{CsCH}_{3} \mathrm{SO}_{3}$, $10 \mathrm{mmol} / \mathrm{l} \mathrm{CsCl}, 10 \mathrm{mmol} / 1 \mathrm{KCl}, 1 \mathrm{mmol} / 1 \mathrm{MgCl}_{2}$ and $5 \mathrm{mmol} /$ 1 HEPES, with $\mathrm{pH}$ adjusted to 7.35 using $\mathrm{CsOH}$.

Detection of insulin release Insulin release from beta cells was measured by ELISA as previously described [25]. For ELISA, we used Krebs-Ringer buffer (KRB; $5 \mathrm{mmol} / \mathrm{l} \mathrm{KCl}$, $120 \mathrm{mmol} / \mathrm{l} \mathrm{NaCl}, 15 \mathrm{mmol} / \mathrm{l}$ HEPES, pH 7.4, $24 \mathrm{mmol} / \mathrm{l}$ $\mathrm{NaHCO}_{3}, 1 \mathrm{mmol} / 1 \mathrm{MgCl}_{2}, 2 \mathrm{mmol} / \mathrm{CaCl}_{2}$ and $1 \mathrm{mg} / \mathrm{ml}$ BSA). Cells were treated with $105 \mathrm{mmol} / 1 \mathrm{KCl}$ for $1 \mathrm{~min}$ and the incubation solution was then collected for analysis. After incubation for 10 min with KRB (vehicle), PKA blocker (H-89) or ADCY8 blocker (2',5'-dideoxyadenosine [DDA]), cells were treated with $\mathrm{KCl}$ for a further $1 \mathrm{~min}$. All samples were then centrifuged at $16,000 \mathrm{~g}$ for $5 \mathrm{~min}$, and insulin levels in the supernatants were determined.

Statistical analysis All data were collected and analysed using Igor software (WaveMetrix, Lake Oswego, OR, USA). The means \pm SEM were calculated, and the Student's $t$ test was used to compare treatment effects. Statistical significance was set at $p<0.05$.

\section{Results}

Depolarisation induces PKA activation in pancreatic beta cells AKAR3, a genetically encoded fluorescent PKA reporter, was used to visualise PKA activity in beta cells. AKAR3 is a fusion peptide comprising cyan fluorescent protein (CFP), a phosphoamino acid-binding domain (14-3-3 $\tau$ ), a PKAspecific phosphorylatable peptide and yellow fluorescent protein (YFP). 14-3-3 $\tau$ mediates signal transduction by binding to a PKA-phosphorylated substrate peptide. The resulting intramolecular conformational change alters the distance between CFP and YFP, thus leading to a reversible FRET signal [22]. As expected, when AKAR3 was transfected into primary beta cells, fluorescence was homogeneously distributed within the cytoplasm (Fig. 1e). The addition of $100 \mu \mathrm{mol} / 1$ 3-isobutyl-1methylxanthine (IBMX; a PDE inhibitor) increased PKA activity, as shown by an increase in $\Delta \mathrm{R}$ (Fig. 1a, d; $n=13$ ). Therefore, the AKAR3 probe can detect changes in PKA activity in live primary beta cells.

Stimulation of cells with $105 \mathrm{mmol} / \mathrm{KCl}$ for $25 \mathrm{~s}(n=14)$ also evoked a robust increase in $\Delta \mathrm{R}$, comparable with that evoked by IBMX, followed by a slower (1-2 $\mathrm{min}$ ) return to baseline (Fig. 1b, d). This $\Delta \mathrm{R}$ value could not have been affected by intracellular $\mathrm{pH}$ because the $\mathrm{pH}$ did not alter during $\mathrm{KCl}$ treatment (ESM Fig. 1). A longer depolarisation period (100 s, $n=10)$ did not lead to a further increase in $\Delta \mathrm{R}$ (Fig. 1c, d), but was associated with a longer recovery time (time constant, tau) to the basal level (tau $=171 \pm 45 \mathrm{~s})$. In contrast, a longer application of IBMX $(n=10)$ induced a much greater increase in $\Delta \mathrm{R}(0.42 \pm 0.05)$, but with a similar recovery time (tau $=54 \pm 9 \mathrm{~s}$ ) as that following a $25 \mathrm{~s}$ IBMX treatment (Fig. 1c, d). Therefore, membrane depolarisationinduced PKA activity is saturable and reaches its peak value after $25 \mathrm{~s} \mathrm{KCl}$ stimulation.

Rather than generating persistent membrane depolarisation, as seen with $\mathrm{KCl}$, glucose induces short trains of action potential spikes in beta cells [15, 26]. Therefore, we used a perforated whole-cell voltage clamp, which keeps most of the intracellular metabolites intact during recording [3], to measure PKA activity evoked by a single depolarisation event. A $500 \mathrm{~ms}$ single-step depolarisation from -70 to 


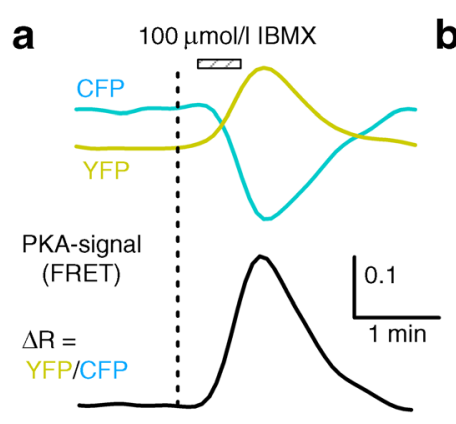

b $105 \mathrm{mmol} / \mathrm{l} \mathrm{KCl}$
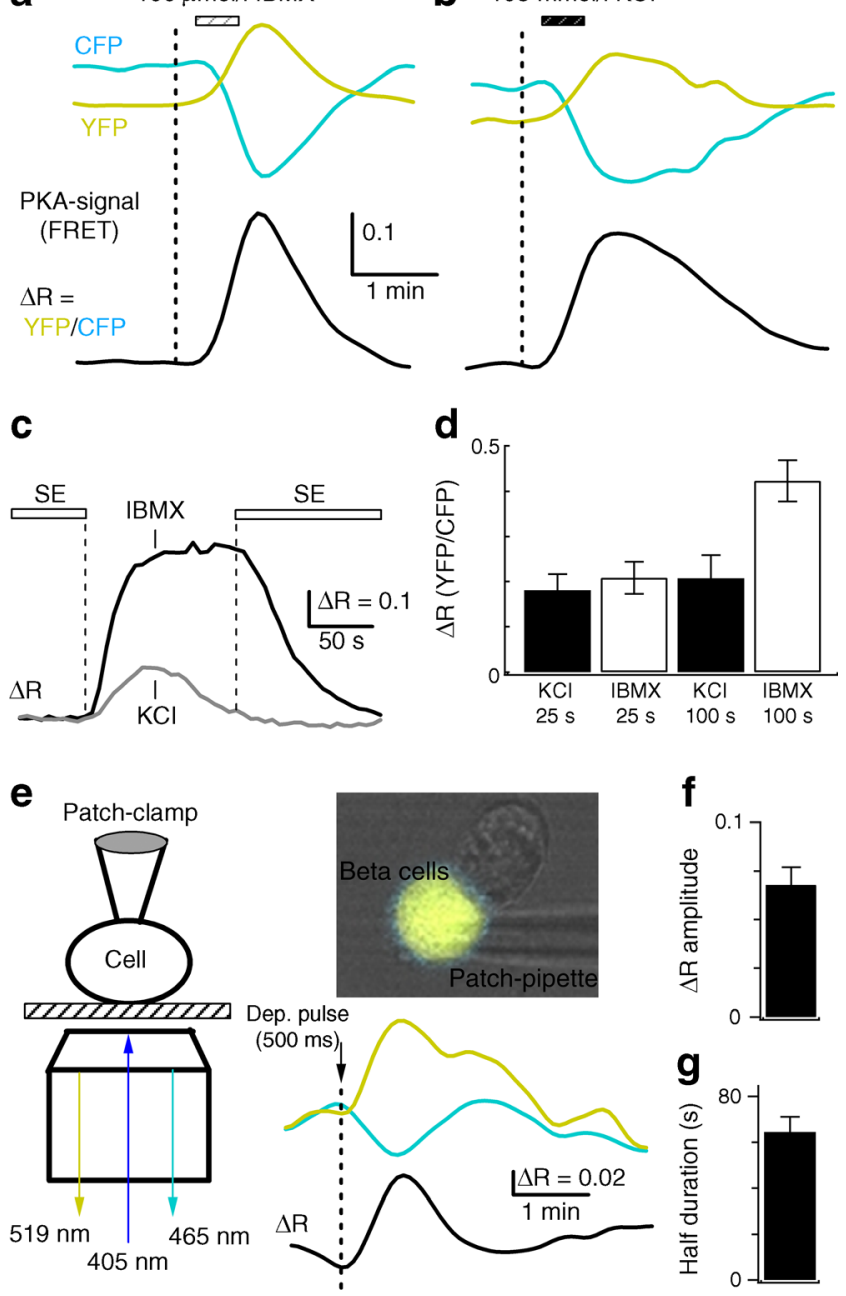

Fig. 1 FRET imaging of depolarisation-induced PKA activation in primary beta cells. (a, b) Changes in CFP (cyan) and YFP (yellow) signal intensity and $\Delta \mathrm{R}$ (black) during the application of $100 \mu \mathrm{mol} / \mathrm{I} \mathrm{IBMX}$ or $105 \mathrm{mmol} / \mathrm{K} \mathrm{KCl}$ for $25 \mathrm{~s}$ to pancreatic beta cells. (c) $\Delta \mathrm{R}$ changes during the application of $100 \mu \mathrm{mol} / 1 \mathrm{IBMX}$ or $105 \mathrm{mmol} / 1 \mathrm{KCl}$ for $100 \mathrm{~s}$ to the same cells $(n=10)$. (d) Summary of $\Delta \mathrm{R}$ changes, as measured in $(\mathbf{a}-\mathbf{c})$. (e) Experimental set-up and representative patch-clamp recording of AKAR3-expressing beta cells. Changes in CFP and YFP intensity and $\Delta \mathrm{R}$ during a single $500 \mathrm{~ms}$ depolarisation event from $-70 \mathrm{mV}$ to $0 \mathrm{mV}$ are also shown. (f, $\mathbf{g}) \Delta \mathrm{R}$ amplitude and half duration of FRET signals, as described in (e) ( $n=8$ out of 32 responsive cells). Dep., depolarisation; $\mathrm{SE}$, standard extracellular solution

$0 \mathrm{mV}$, which is comparable with glucose-induced depolarisation, increased PKA activity in $25 \%$ of recorded beta cells (Fig. 1e, f; $\Delta \mathrm{R}=0.08 \pm 0.01, n=8$ out of 32 recorded cells). Although the $\Delta \mathrm{R}$ increase was smaller, the recovery rate ( $\operatorname{tau}=94 \pm 19 \mathrm{~s})$ after depolarisation was similar to that induced by $25 \mathrm{~s} \mathrm{KCl}$ stimulation (Fig. 1e, f). Thus, physiologically relevant depolarisation conditions can activate PKA in a proportion of beta cells.

Depolarisation-induced PKA activation is $\mathrm{Ca}^{2+}$ dependent To directly assess the temporal relationship between a depolarisation-evoked increase in $\left[\mathrm{Ca}^{2+}\right]_{\mathrm{i}}$ and PKA activation, we preloaded AKAR3-transfected beta cells with the $\mathrm{Ca}^{2+}$ indicator, Rhod-2 AM. The $\left[\mathrm{Ca}^{2+}\right]_{\mathrm{i}}$ increased rapidly following the application of $105 \mathrm{mmol} / \mathrm{KCl}$ and then rapidly decreased to the basal level (Fig. 2c-e, rise time $(\mathrm{RT})=$ $27 \pm 2 \mathrm{~s} ;$ tau $=63 \pm 15 \mathrm{~s}, n=11)$. These results contrast with the much slower changes in PKA activity (Fig. 2a, c; RT $=59 \pm 5 \mathrm{~s}$; tau $=116 \pm 24 \mathrm{~s}, n=7)$. Latency between the maximum $\left[\mathrm{Ca}^{2+}\right]_{\mathrm{i}}$ and $\Delta \mathrm{R}$ peaks was $28 \pm 5 \mathrm{~s}$, indicating that PKA activation lags $\left[\mathrm{Ca}^{2+}\right]_{\mathrm{i}}$ elevation (Fig. 2f).

This temporal association suggests a causal relationship between increased $\left[\mathrm{Ca}^{2+}\right]_{\mathrm{i}}$ and PKA activation. To test this possibility, cells were sequentially stimulated with a $\mathrm{KCl}$ solution containing $2.6 \mathrm{mmol} / 1$ or $0 \mathrm{mmol} / 1 \mathrm{Ca}^{2+}$ for $25 \mathrm{~s}$. When cells were depolarised in the $\mathrm{Ca}^{2+}$-free solution, there was no PKA activation (Fig. 2a, b; $n=7$ ); however, the addition of $2.6 \mathrm{mmol} / 1 \mathrm{Ca}^{2+}$ partially restored PKA activation. Therefore, depolarisation-induced PKA activation is $\mathrm{Ca}^{2+}$ dependent.

When isolated single cells were challenged with $20 \mathrm{mmol} / \mathrm{l}$ glucose, oscillatory changes in PKA activity occurred at a frequency of approximately $0.3 / \mathrm{min}$ (Fig. $3 \mathrm{a} ; n=8$ ).

a
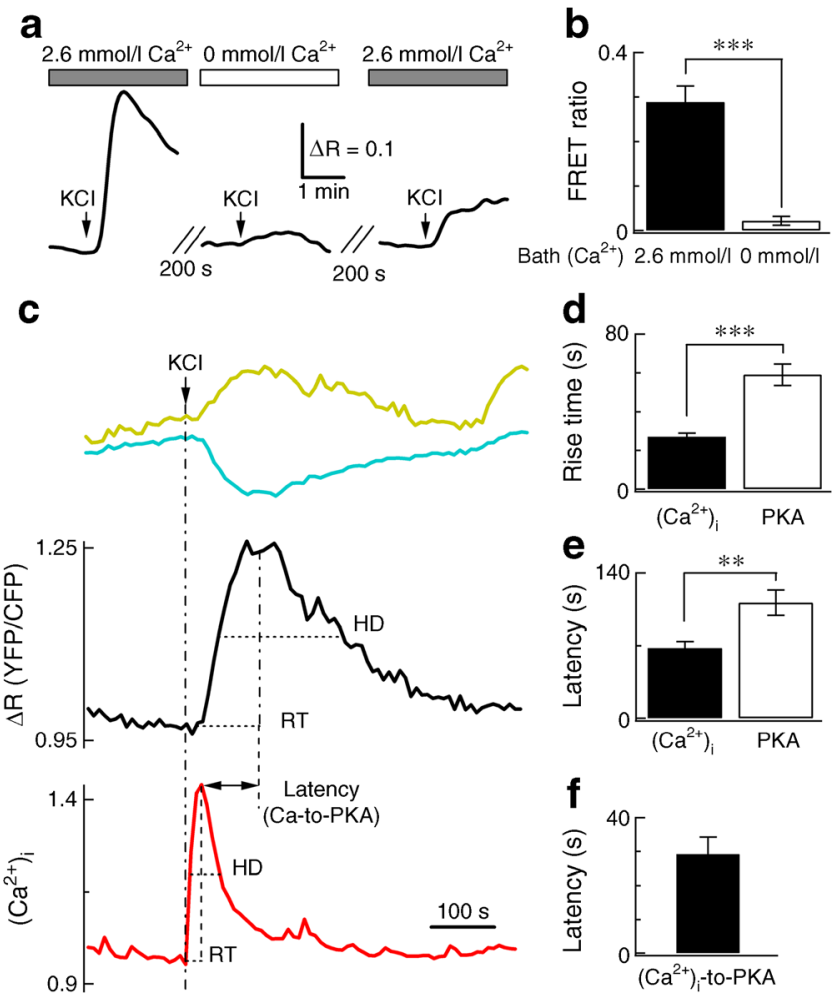

Fig. 2 Depolarisation-induced PKA activation is $\mathrm{Ca}^{2+}$-dependent in primary beta cells. (a) Depolarisation-induced PKA changes in single beta cells suspended in $2.6 \mathrm{mmol} / 1 \mathrm{Ca}^{2+}$ or $0 \mathrm{mmol} / 1 \mathrm{Ca}^{2+}$ containing $2 \mathrm{mmol} / \mathrm{l}$ EGTA $(n=7)$. (b) Graph showing PKA signals, as measured in (a). $(\mathbf{c}-\mathbf{f})$ Simultaneous recordings of FRET and $\left[\mathrm{Ca}^{2+}\right]_{\mathrm{i}}$ in single beta cells $(n=11)$. $\left[\mathrm{Ca}^{2+}\right]_{\mathrm{i}}$ was measured using Rhod-2 AM. RT, rise time; HD, half-height duration; Latency (Ca-to-PKA), latency between $\left[\mathrm{Ca}^{2+}\right]_{\mathrm{i}}$ and PKA signal peaks; ${ }^{* *} p<0.01 ; * * * p<0.001$ 


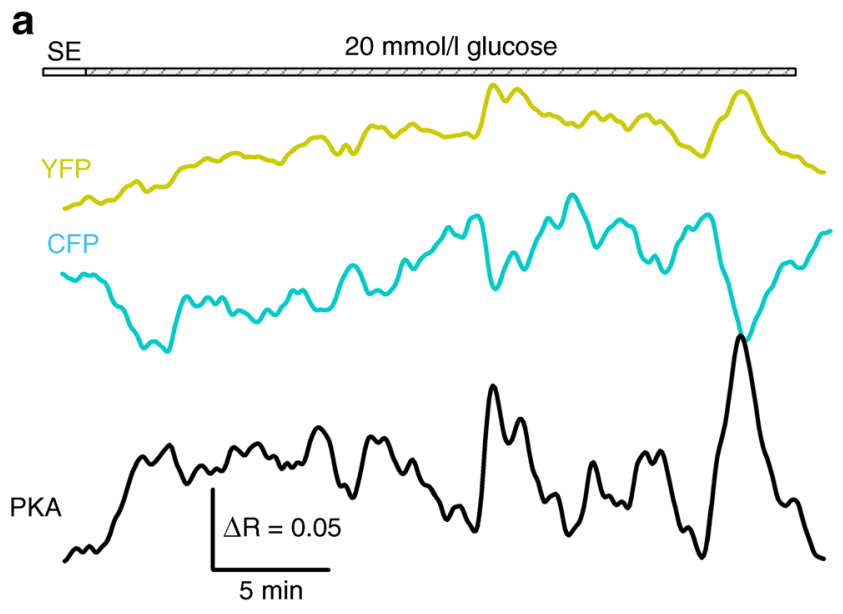

b

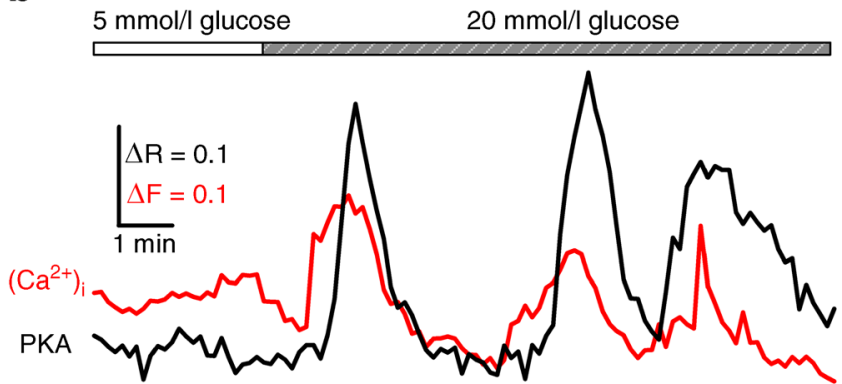

Fig. 3 Glucose-induced PKA oscillations are coupled to $\left[\mathrm{Ca}^{2+}\right]_{\text {i }}$ oscillations in beta cells. (a) PKA oscillations induced by $20 \mathrm{mmol} / 1$ glucose $(n=8)$. (b) Simultaneous recording of oscillatory $[\mathrm{Ca}]_{\mathrm{i}}(\Delta \mathrm{F}$, red $)$ and PKA ( $\Delta \mathrm{R}$, black) signals induced by $20 \mathrm{mmol} / \mathrm{l}$ glucose in a representative cell bathed in standard extracellular solution (SE) $(n=5)$

Simultaneous monitoring of $\left[\mathrm{Ca}^{2+}\right]_{\mathrm{i}}$ and PKA activity showed a good temporal association between $\left[\mathrm{Ca}^{2+}\right]_{\mathrm{i}}$ spikes and $\Delta \mathrm{R}$ spikes (Fig. 3b), implying a link between $\mathrm{Ca}^{2+}$ influx and PKA activation in glucose-mediated physiological processes, including glucose-stimulated insulin secretion.

ADCY8 is required for $\mathrm{Ca}^{2+}$-dependent PKA activation $\mathrm{Ca}^{2+}$ modulates the intracellular free cAMP concentration $\left([\mathrm{cAMP}]_{\mathrm{i}}\right)$ and PKA activity via either $\mathrm{Ca}^{2+}$-sensitive ADCY or $\mathrm{Ca}^{2+}$-sensitive PDE [27]. Because depolarisation $/ \mathrm{Ca}^{2+}$-induced PKA activation showed different kinetics (slower decay rate) from those evoked by PDE inhibition (Fig. 1a, b), we speculated that ADCYs may play an important role. ADCY8 is activated by $\mathrm{Ca}^{2+} /$ calmodulin and participates in glucoseand GLP-1-mediated cAMP production in pancreatic beta cells $[13,28]$. We therefore used RNA interference (RNAi)based ADCY8 KD to determine the role of ADCY8 in depolarisation-evoked PKA activation.

ADCY8 was efficiently silenced by ADCY8 short hairpin RNA (sh-ADCY8) transfection; a scrambled short hairpin RNA served as control (sh-Ctr). This effect was completely reversed by expression of a short hairpin RNA-resistant form of ADCY8 ('rescue') in INS-1 cells (Fig. 4a, b; $n=3$ ).
Membrane depolarisation with $105 \mathrm{mmol} / \mathrm{KCl}$ induced a robust $\Delta \mathrm{R}$ increase in sh-Ctr-expressing cells (Fig. 4c, f; $\Delta \mathrm{R}=0.08 \pm 0.02, n=20)$, but failed to activate PKA in most ADCY8-KD cells (Fig. 4d, f; $\Delta \mathrm{R}=0.017 \pm 0.014, n=18$ ). Treatment with $100 \mu \mathrm{mol} / 1$ IBMX (positive control) evoked similar $\triangle \mathrm{R}$ changes in both $\mathrm{ADCY} 8 \mathrm{KD}$ and control cells (Fig. 4c, d). Depolarisation-evoked PKA activation was probably caused by reduced ADCY8 expression because it was completely rescued by ADCY8 overexpression (Fig. 4e, f; $\Delta \mathrm{R}=0.17 \pm 0.04, n=5)$. Therefore, ADCY 8 mediates depolarisation-evoked PKA activation in rat primary beta cells.

Depolarisation-induced PKA activation replenishes depleted vesicle pools To investigate the role of PKA in vesicle pool replenishment, we stimulated primary beta cells with
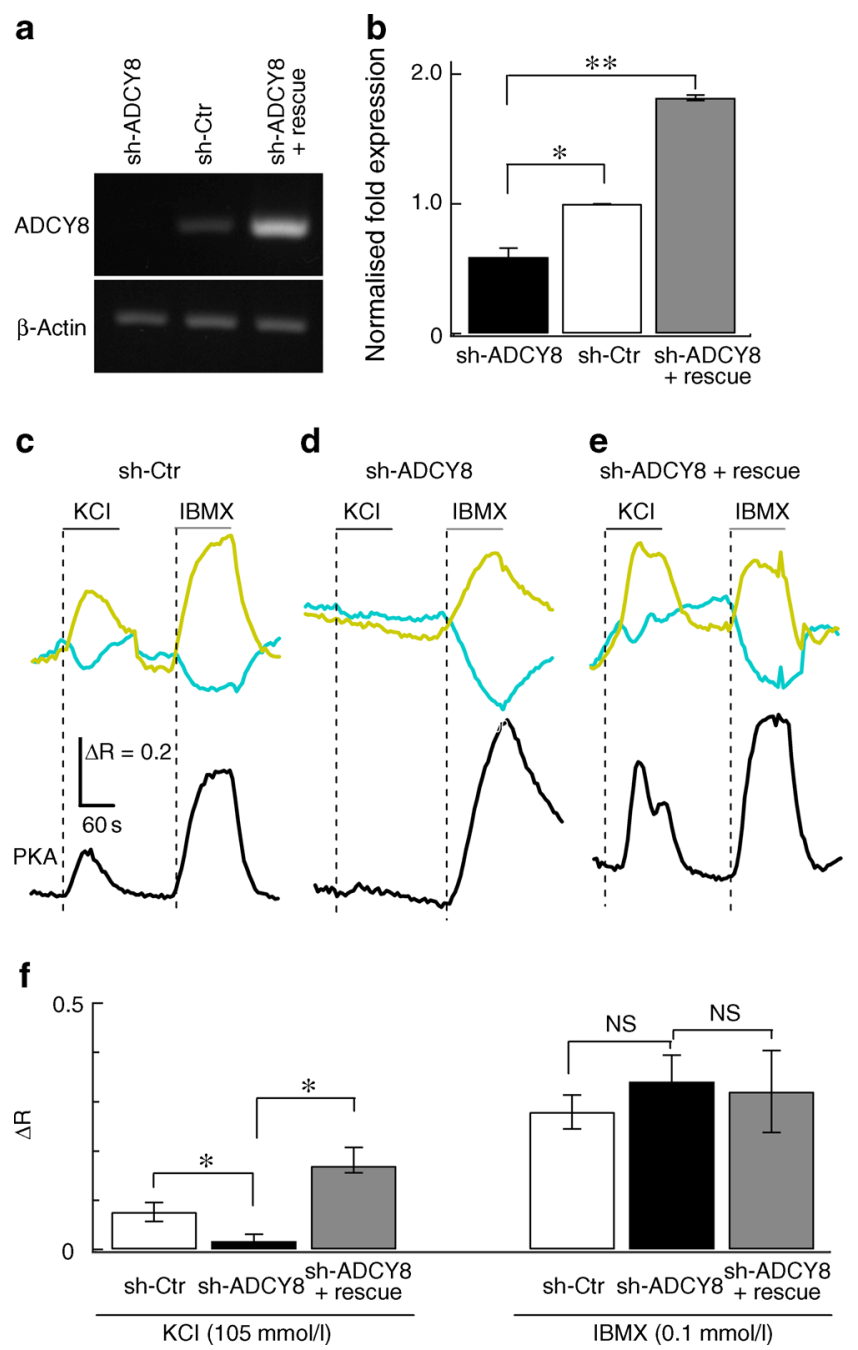

Fig. 4 ADCY8 is required for $\mathrm{Ca}^{2+}$-dependent PKA activation in pancreatic beta cells. (a, b) Sh-ADCY8 KD and rescue efficiency in INS-1 cells, as assessed by RT-PCR and real-time PCR $(n=3)$. (c-e) PKA changes induced by high $\mathrm{KCl}$ and IBMX in control (sh-Ctr; $n=20$ ), ADCY8-KD (sh-ADCY8; $n=18$ ) and rescued (sh-ADCY8 + rescue; $n=5$ ) beta cells. (f) Graphs summarising results from $(\mathbf{c}-\mathbf{e}) . p<0.05$; $* * p<0.01$ 
depolarising pulse (or stimulus) trains from -70 to $0 \mathrm{mV}$ at $100 \mathrm{~ms}$ intervals, and simultaneously measured $\Delta \mathrm{R}$ (i.e. PKA activity) and $\mathrm{C}_{\mathrm{m}}$ (i.e. exocytosis) in single beta cells (Fig. 5a). Each pulse train comprised five $50 \mathrm{~ms}$ depolarising pulses to deplete the immediately releasable pool (IRP1), followed by eight $500 \mathrm{~ms}$ depolarising pulses to induce exocytosis from the readily releasable pool (RRP1) [29]. A second identical stimulus pulse train was repeated 2 min after the first pulse train (IRP2 and RRP2, respectively). Recovery was estimated

a

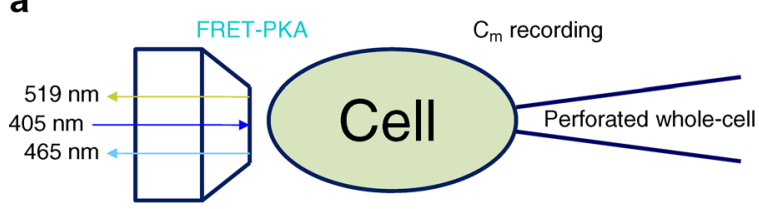

b
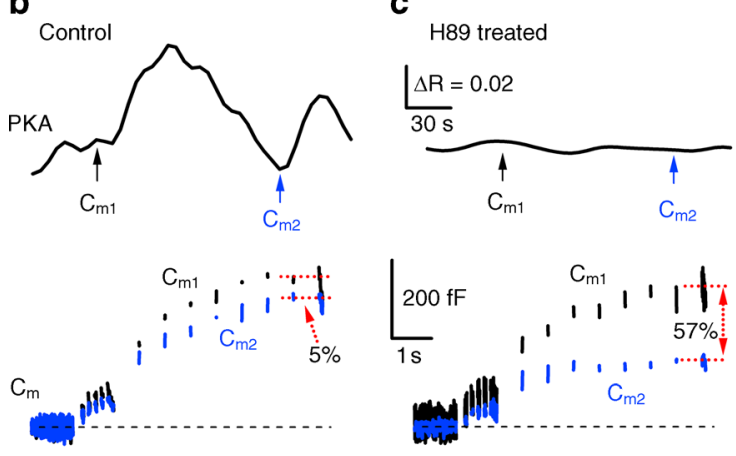

d

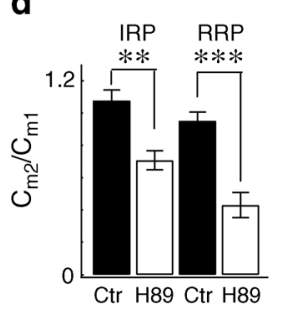

e

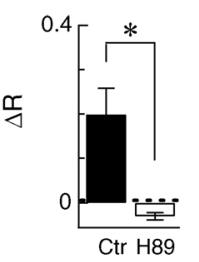

f

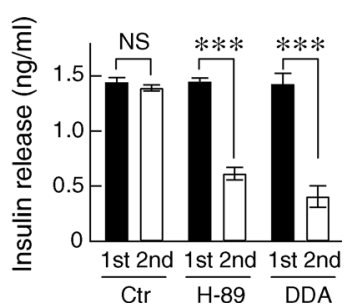

Fig. 5 Depolarisation-induced PKA activation is responsible for vesicle pool replenishment. (a) Representation showing simultaneous recording of PKA activity $(\Delta \mathrm{R})$ and $\mathrm{C}_{\mathrm{m}}$ (exocytosis). (b) A train of depolarising pulses from $-70 \mathrm{mV}$ to $0 \mathrm{mV}$ using voltage clamp-induced PKA (above) and exocytosis (below) signals in a single beta cell using a perforated whole-cell configuration. The stimulus train consisted of five $50 \mathrm{~ms}$ pulses to deplete vesicles from the IRP followed by eight $500 \mathrm{~ms}$ pulses to elicit exocytosis from the RRP, with $100 \mathrm{~ms}$ intervals between pulses. The stimulus trains were repeated twice, with a 2 min intervals between the first $\left(\mathrm{C}_{\mathrm{m} 1}\right.$, black) and second $\left(\mathrm{C}_{\mathrm{m} 2}\right.$, blue $)$ stimulus train to allow vesicle pool replenishment. (c) Similar to (b) except that $15 \mu \mathrm{mol} / 1$ H-89 (PKA inhibitor) was present in the patch pipette. (d, e) Graphs showing $\mathrm{C}_{\mathrm{m} 2} / \mathrm{C}_{\mathrm{m} 1}$ ratios for IRP and RRP (d) and PKA (e) evoked by the first pulse train in control $(n=5)$ and $\mathrm{H}-89$ treated $(n=6)$ cells. (f) PKA activation is responsible for sustained insulin release from beta cells. Insulin release was stimulated by two pulses of $\mathrm{KCl}(105 \mathrm{mmol} / \mathrm{l}$, $1 \mathrm{~min} ; 10 \mathrm{~min}$ interval) and measured by ELISA. H-89 $(15 \mu \mathrm{mol} / \mathrm{l})$ or DDA $(100 \mu \mathrm{mol} / \mathrm{l})$ significantly inhibited insulin release following the second stimulus to $0.42(p<0.01)$ and $0.25(p<0.01) \mathrm{ng} / \mathrm{ml}$, respectively $(n=4) . p<0.05 ; * * p<0.01 ; * * * p<0.001$ by determining the IRP2/IRP1 and RRP2/RRP1 ratios in the same cells.

Typically, the first depolarising pulse train led to an increase in $\Delta \mathrm{R}$ comparable to that evoked by a $100 \mathrm{~s} \mathrm{KCl}$ stimulation (Fig. 5b, e; $\Delta \mathrm{R}=0.20 \pm 0.06, n=5$ ). The second pulse train was applied approximately $100 \mathrm{~s}$ later, when the cytoplasmic PKA activity had returned to the basal level (Fig. 5b). Under control conditions, $\mathrm{C}_{\mathrm{m}}$ changes triggered by the second pulse train were similar to those triggered by the first (Fig. 5b, d; IRP2/IRP1 1.08 \pm 0.07 , RRP2/RRP1 0.95 \pm 0.05 ), indicating complete replenishment of both pools (IRP and RRP). In contrast, 7-10 min after cell dialysis with a patch pipette containing H-89 (a membrane-permeable PKA inhibitor [30]), no increase in $\Delta \mathrm{R}$ was induced by the first or second depolarising pulse train (Fig. 5c, e), indicating a complete blockade of PKA activation by $\mathrm{H}-89$. The IRP $(75 \pm 12$ $\mathrm{fF})$ and RRP $(279 \pm 18 \mathrm{fF})$ induced by the first depolarising pulse train remained unchanged in the presence of $\mathrm{H}-89$. However, the recovery of these pools before the second pulse train was severely impaired by PKA inhibition (Fig. 5c, d; IRP2/IRP1 0.71 \pm 0.06, RRP2/RRP1 $0.43 \pm 0.08, n=6$ ).

Next, we examined insulin release from dispersed islet beta cells using ELISA. Two sequential depolarisation events $10 \mathrm{~min}$ apart each triggered almost the same amount of insulin release in control cells (Fig. 5f). However, cells treated with either H-89 or the transmembrane ADCY inhibitor DDA during the interval between depolarising pulse trains exhibited significantly less insulin release in response to the second vs the first stimulus (Fig. 5f; $n=4$ for each experimental condition). Consistent with this, Rp-cAMPS, a more selective cAMP/PKA inhibitor, had similar inhibitory effects on both phases of glucose-induced insulin secretion (ESM Fig. 2). Taken together, these findings suggest that PKA activity stimulated by depolarisation and/or $\mathrm{Ca}^{2+}$ entry plays a central role in refilling insulin vesicle pools in rat primary beta cells.

ADCY8 activation facilitates sustained vesicle fusion Similar levels of PKA activation were induced by either a standard depolarising pulse train lasting for $5 \mathrm{~s}$ or a $100 \mathrm{~s} \mathrm{KCl} \mathrm{stimu-}$ lation (Figs $1 \mathrm{~d}$ and 5e), suggesting that $\mathrm{Ca}^{2+}$ influx evoked by a 5 s pulse train maximally activates ADCY8 and PKA upon membrane depolarisation. In addition to $\mathrm{Ca}^{2+}, \mathrm{GLP}-1$ is known to activate ADCY8 via stimulation of the GLP-1 receptor [28]. In primary beta cells, $100 \mathrm{nmol} / 1$ GLP-1 evoked a much greater level of PKA activation compared with $\mathrm{KCl}$ (ESM Fig. $3 ; n=5$ ). GLP-1-induced PKA activity was reduced by approximately $60 \%$ in ADCY8-KD cells (ESM Fig. 4), suggesting that ADCY 8 also has a major role in hormoneinduced cAMP/PKA activation. In addition, ADCY8 KD had a greater effect on GLP-1-triggered PKA activation (approximately $60 \%$ reduction; ESM Fig. 4) than on PKA activation evoked by membrane depolarisation (Fig. 4f), indicating that membrane depolarisation does not activate all of the 
functional ADCY8 in beta cells. To confirm that the $\mathrm{Ca}^{2+}$ responsive ADCY8 subpool is functionally important, we used a standard whole-cell patch-clamp configuration with an ATP- and CAMP-free intracellular solution to examine the role of ADCY8 in vesicle pool replenishment. In sh-Ctrexpressing cells, the increase in $\mathrm{C}_{\mathrm{m}}$ induced by the second depolarising pulse train was somewhat lower than that of the first pulse train (by 33\%) as a result of rundown (Fig. 6a, c; IRP2/IRP1 $0.97 \pm 0.19$, RRP2/RRP1 $0.67 \pm 0.07$; but see [5]). Thus, in control cells, the first pulse train evoked transient PKA activation that causes refilling of most of the IRP and RRP. In ADCY8-KD cells, the depolarisation-induced $\left[\mathrm{Ca}^{2+}\right]_{\mathrm{i}}$ rise was intact (ESM Fig. $5 ; n=11$ ) and the first pulse train induced a $\mathrm{C}_{\mathrm{m}}$ increase similar to that of control cells (Fig. 6b, c; IRP $15.0 \pm 2.8 \mathrm{fF}$, RRP $85.6 \pm 17.1 \mathrm{fF}$ ); however, secretion induced by the second pulse train was dramatically impaired (Fig. 6b, d; IRP2/IRP1 $0.42 \pm 0.12$, RRP2/RRP1 $0.35 \pm 0.09)$. The recovery rate was markedly slower in ADCY8-KD cells than in control cells (Fig. 6a, d), indicating that replenishment of vesicle pools is impaired by ADCY8 KD. Taken together, these data suggest that activation of ADCY 8 by depolarisation is responsible for replenishing insulin vesicle pools in rat beta cells. a
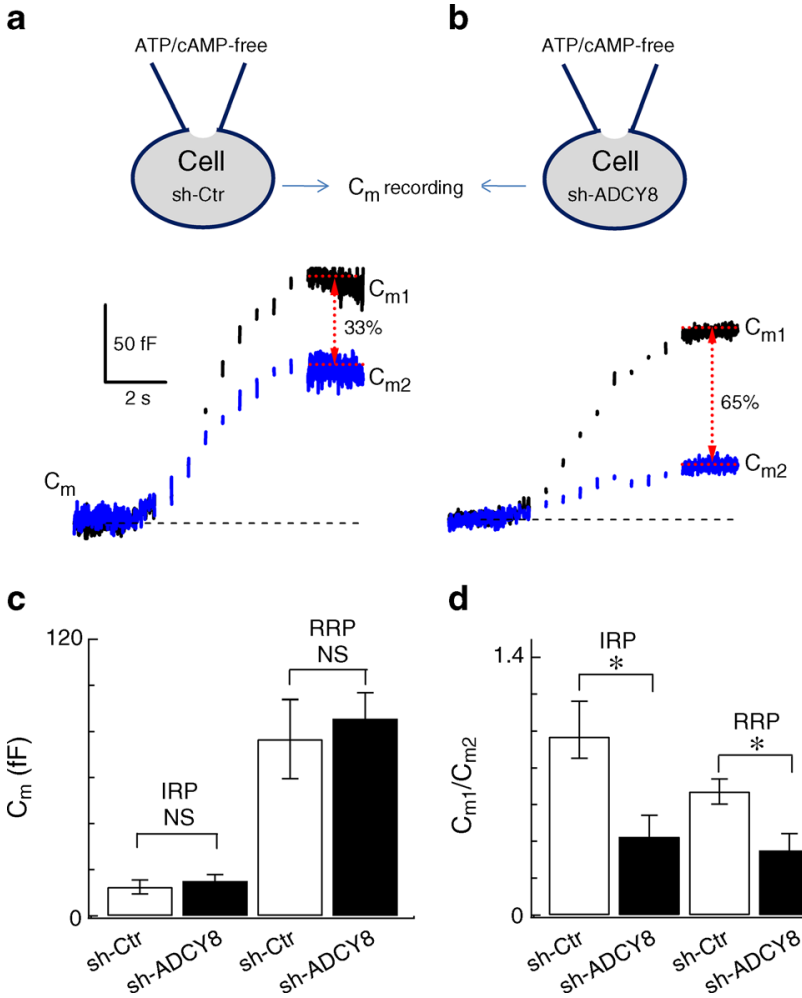

d

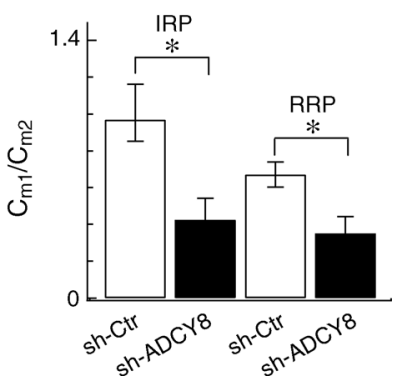

Fig. $6 \mathrm{ADCY} 8$ is responsible for vesicle pool replenishment. (a, b) $\mathrm{C}_{\mathrm{m}}$ recordings under whole-cell dialysis with an ATP- and cAMP-free solution in ADCY8 KD $(n=11)$ and control $(n=6)$ cells. (c, d) Graphs summarising exocytosis and $\mathrm{C}_{\mathrm{m} 2} / \mathrm{C}_{\mathrm{m} 1}$ ratios for both IRP and RRP induced by the first pulse train, from $(\mathbf{a}, \mathbf{b}) . p<0.05$

\section{Discussion}

A major finding of the present study is that depolarisationinduced $\mathrm{Ca}^{2+}$ influx has dual effects on insulin release in beta cells, by directly triggering vesicle fusion (for instant release) and indirectly promoting vesicle replenishment (for sustained release). Regarding the relationship between $\mathrm{Ca}^{2+}$ and vesicle pools, it has been established that intracellular $\mathrm{Ca}^{2+}$ triggers vesicle release via stimulating $\mathrm{Ca}^{2+}$-dependent vesicle fusion to the plasma membrane in neurons and endocrine cells [24, 31-33], including beta cells [25, 34-36]. However, multiple mechanisms have been proposed to promote vesicle pool replenishment in excitable cells. In chromaffin cells and neurons, it is known that basal $\left[\mathrm{Ca}^{2+}\right]_{\mathrm{i}}$ level can modulate the vesicle pool [37, 38]. Previous pharmacological experiments established that cAMP also facilitates replenishment of the vesicle pool in beta cells via both PKA-dependent and EPAC2-dependent pathways [2, 4-6, 34]. Here, by combining PKA imaging with $\mathrm{C}_{\mathrm{m}}$ recording, we found that $\mathrm{ADCY} 8$ links the $\mathrm{Ca}^{2+}$ - and cAMP/PKA-dependent pathways (described above) in rat primary beta cells. When using a physiologically relevant stimulation pattern (Fig. 3), the first depolarising pulse train caused not only the first phase of secretion and PKA activation but also facilitated exocytosis/insulin release induced by the second pulse train through vesicle pool replenishment supported by PKA activation (Figs 5 and 6). These findings suggest that $\mathrm{Ca}^{2+}$ - and ADCY8-dependent PKA pathways may also play critical roles in promoting sustained insulin release upon glucose challenge under physiological conditions.

The second important finding is the causal link between depolarisation-induced $\mathrm{Ca}^{2+}$ entry and enhanced PKA activity in rat primary beta cells. Previous studies using genetic indicators of cAMP levels in clonal MIN6 cells showed coordinated glucose-stimulated oscillations in $\mathrm{Ca}^{2+}$ and cAMP [14, 20], as well as $\mathrm{Ca}^{2+}$ influx and an ADCY8-induced cAMP signal [39]. A recent study reported that $\mathrm{Ca}^{2+}$ and cAMP oscillate in synchrony and that PKA activity lags behind cAMP changes such that an increase in PKA activity precedes the next round of $\mathrm{Ca}^{2+}$ signalling after depolarisation in MIN6 cells [15]. Differences between stimuli ( $\mathrm{KCl} /$ glucose vs TEA) may account for the observed differences in lag times between different signals. In the present study, we demonstrated that a physiologically relevant depolarisation-triggered transient increase in $\left[\mathrm{Ca}^{2+}\right]_{\mathrm{i}}$ precedes the transient PKA activation by $28 \mathrm{~s}$ in primary beta cells (Fig. 2c). Moreover, the depolarisationevoked PKA activation was abolished by removing extracellular $\mathrm{Ca}^{2+}$ (Fig. 2a, b). Glucose-stimulated PKA activity was also coupled to $\left[\mathrm{Ca}^{2+}\right]_{i}$, although the lag time and the waveform linking them were variable (Fig. 3b). This variation may be caused by glucose promotion of cAMP production via metabolic coupling factors unrelated to $\mathrm{Ca}^{2+}[11,20,40]$. These results established the important contribution of 
elevated $\left[\mathrm{Ca}^{2+}\right]_{\mathrm{i}}$ to activation of the glucose-triggered cAMP/PKA pathway in native beta cells, as distinct from previous studies using cell lines.

Our third finding is that an ADCY8 subpool in beta cell contributes to depolarisation-induced PKA activation. ADCY8 is an important mediator of cAMP accumulation evoked by incretin stimulation [28]. Previous studies also revealed that A kinase-anchoring protein 79/150 (AKAP79/ 150) specifically interacts with ADCY 8 and thus has the potential to produce localised cAMP signalling evoked by local $\mathrm{Ca}^{2+}$ entry [41]. Here, we showed that the level of PKA activation following depolarisation triggered by $105 \mathrm{mmol} / 1 \mathrm{KCl}$ perfusion for $25-100 \mathrm{~s}$ was similar to that triggered by patch-clamp depolarisation for $\leq 5 \mathrm{~s}$ (Figs 1 and 5). This was not a consequence of probe saturation because $100 \mathrm{~s}$ IBMX evoked an even greater response in the same cells (Fig. 1c, d). Instead, our interpretation of the data is that an ADCY8 subpool is activated by membrane depolarisation. Although ADCY8 is almost completely absent from human beta cells [12, 42], this finding may help to reveal the roles of other ADCY isoforms, such as ADCY5, which is involved in human islet function [12].
In a physiological context, each wave within the glucoseinduced membrane potential oscillations may maximally and repeatedly activate a proportion of the cAMP/PKA pathway. As shown in Fig. 3, PKA peaks triggered by $20 \mathrm{mmol} / \mathrm{l}$ glucose had a similar amplitude and dynamics to those evoked by a single train of depolarisation. Such an arrangement ensures sustained insulin vesicle trafficking and secretion in single primary beta cells. Here, consistent with previous reports [13, 40, 43], GLP-1 evoked a much greater level of PKA activation than that evoked by depolarisation alone (ESM Fig. 3), suggesting that incretins activate an additional ADCY8 subpool [43]. ADCY8 proteins activated at later time points may be more distant from VGCCs and thus incapable of activation by the depolarisation-induced $\mathrm{Ca}^{2+}$ influx alone (Fig. 7). Figure 7 summarises the results of present study: glucose stimulation generates a transient microdomain of high $\left[\mathrm{Ca}^{2+}\right]_{\mathrm{i}}$ that promotes insulin secretion through dual pathways, i.e. by directly triggering vesicle fusion and indirectly activating ADCY8/PKA to enhance vesicle pool replenishment. A VGCC-coupled ADCY8 subpool plays a central role in $\mathrm{Ca}^{2+}$ evoked PKA activation, which is partially responsible for glucose- and GLP-1-stimulated cAMP production. This study
Fig. 7 Proposed model for the control of insulin release by the glucose/ $\mathrm{Ca}^{2+} / \mathrm{ADCY} 8$ pathway. (a) Following an increase in blood glucose (1), the GLUT delivers glucose into beta cells (2), followed by a mitochondriamediated increase in the cytosolic ATP/ADP ratio (3). This change leads to $\mathrm{K}_{\text {ATP }}$ channel closure (4) and action potential firing (5). During membrane depolarisation, VGCCs open (6), leading to increased $\left[\mathrm{Ca}^{2+}\right]_{\mathrm{i}}(7)$, which triggers insulin vesicle exocytosis (8a). Increased $\left[\mathrm{Ca}^{2+}\right]_{\mathrm{i}}$ also stimulates ADCY8 activation (8), leading to cAMP production (9) and PKA activation (10). PKA activation is responsible for vesicle pool replenishment (11) and maintaining insulin secretion (12). Incretins (such as GLP-1) activate the additional VGCCinsensitive ADCY8 subpool and can trigger higher levels of cAMP/PKA pathway activation compared with depolarisation. (b) PKA activation stimulates reserve pool vesicles into the RRP necessary for sustained insulin secretion. Mito, mitochondrion a
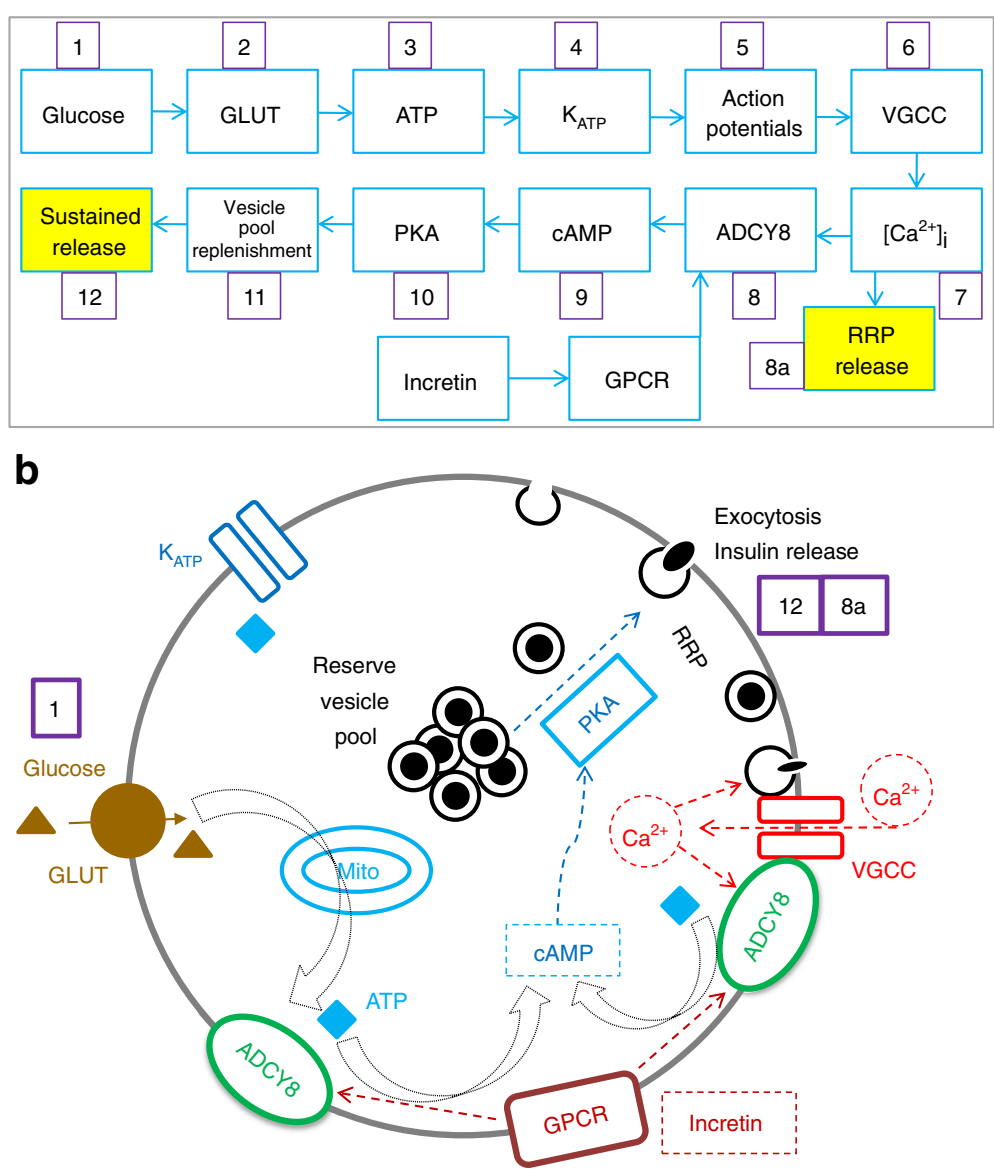
has improved our understanding of glucose- and $\mathrm{Ca}^{2+}$-regulated vesicle trafficking and pulsatile insulin secretion $[2,3$, 44] under normal physiological and diabetic conditions.

Acknowledgements We thank H. Ma (Suzhou Institute of Nano-Tech and Nano-Bionics, Chinese Academy of Sciences, China), T. Xie (College of Engineering, Peking University, China) and S. Chen (College of Engineering, Peking University, China) for training in experimental techniques, I. Bruce (Institute of Molecular Medicine, Peking University, China) for his comments on the manuscript.

Funding This work was supported by grants from the National Basic Research Programme of China (2012CB518006), the National Natural Science Foundation of China (31228010, 31171026, 31100597, 31327901, 81222020, 31221002, 31330024 and 31400708) and the National Key Technology R\&D Programme (SQ2011SF11B01041). Changhe Wang was supported in part by the Postdoctoral Fellowship of Peking-Tsinghua Center for Life Science.

Duality of interest The authors declare that there is no duality of interest associated with this manuscript.

Contribution statement $\mathrm{HD}, \mathrm{CW}, \mathrm{LC}, \mathrm{XY}$ and $\mathrm{ZZ}$ were responsible for conception and design of the study. HD, CW, XW, LY, XZ, ST, HX, BL, QW, QZ, MH, YW, LW, QL, JS, YW, SS, XK and LZ contributed to data acquisition, analysis and interpretation. MR, JL and JZ contributed to data analysis and interpretation. All authors were involved in drafting the manuscript and all approved the final version. $\mathrm{ZZ}$ is the guarantor of this work

\section{References}

1. Tarasov AI, Semplici F, Ravier MA et al (2012) The mitochondrial $\mathrm{Ca} 2+$ uniporter MCU is essential for glucose-induced ATP increases in pancreatic beta-cells. Plos One 7:e39722

2. Ashcroft FM, Rorsman P (2012) Diabetes mellitus and the beta cell: the last ten years. Cell 148:1160-1171

3. Zhou Z, Misler S (1996) Amperometric detection of quantal secretion from patch-clamped rat pancreatic beta-cells. J Biol Chem 271:270 277

4. Renstrom E, Eliasson L, Rorsman P (1997) Protein kinase Adependent and -independent stimulation of exocytosis by cAMP in mouse pancreatic B cells. J Physiol 502(Pt 1):105-118

5. Eliasson L, Ma X, Renstrom E et al (2003) SUR1 regulates PKAindependent cAMP-induced granule priming in mouse pancreatic B cells. J Gen Physiol 121:181-197

6. Shibasaki T, Takahashi H, Miki T et al (2007) Essential role of Epac2/ Rap1 signaling in regulation of insulin granule dynamics by cAMP. Proc Natl Acad Sci U S A 104:19333-19338

7. Gremlich S, Porret A, Hani EH et al (1995) Cloning, functional expression, and chromosomal localization of the human pancreatic islet glucose-dependent insulinotropic polypeptide receptor. Diabetes 44:1202-1208

8. Thorens B (1992) Expression cloning of the pancreatic beta cell receptor for the gluco-incretin hormone glucagon-like peptide 1 . Proc Natl Acad Sci U S A 89:8641-8645

9. Grill V, Cerasi E (1973) Activation by glucose of adenyl cyclase in pancreatic islets of the rat. FEBS Lett 33:311-314

10. Ramos LS, Zippin JH, Kamenetsky M, Buck J, Levin LR (2008) Glucose and GLP-1 stimulate cAMP production via distinct adenylyl cyclases in INS-1E insulinoma cells. J Gen Physiol 132:329-338
11. Dyachok O, Idevall-Hagren O, Sagetorp J et al (2008) Glucoseinduced cyclic AMP oscillations regulate pulsatile insulin secretion. Cell Metab 8:26-37

12. Hodson DJ, Mitchell RK, Marselli L et al (2014) ADCY5 couples glucose to insulin secretion in human islets. Diabetes 63:3009-3021

13. Delmeire D, Flamez D, Hinke SA, Cali JJ, Pipeleers D, Schuit F (2003) Type VIII adenylyl cyclase in rat beta cells: coincidence signal detector/generator for glucose and GLP-1. Diabetologia 46:13831393

14. Landa LR Jr, Harbeck M, Kaihara K et al (2005) Interplay of Ca2+ and cAMP signaling in the insulin-secreting MIN6 beta-cell line. J Biol Chem 280:31294-31302

15. Ni Q, Ganesan A, Aye-Han NN et al (2011) Signaling diversity of PKA achieved via a Ca2+-cAMP-PKA oscillatory circuit. Nat Chem Biol 7:34-40

16. De Marinis YZ, Salehi A, Ward CE et al (2010) GLP-1 inhibits and adrenaline stimulates glucagon release by differential modulation of $\mathrm{N}$ - and L-type Ca2+ channel-dependent exocytosis. Cell Metab 11: $543-553$

17. Kamp TJ, Hell JW (2000) Regulation of cardiac L-type calcium channels by protein kinase A and protein kinase C. Circ Res 87: 1095-1102

18. Kang G, Chepurny OG, Rindler MJ et al (2005) A cAMP and Ca2+ coincidence detector in support of $\mathrm{Ca} 2+$-induced $\mathrm{Ca} 2+$ release in mouse pancreatic beta cells. J Physiol 566:173-188

19. Dyachok O, Gylfe E (2004) $\mathrm{Ca}(2+)$-induced $\mathrm{Ca}(2+)$ release via inositol 1,4,5-trisphosphate receptors is amplified by protein kinase A and triggers exocytosis in pancreatic beta-cells. J Biol Chem 279: 45455-45461

20. Idevall-Hagren O, Barg S, Gylfe E, Tengholm A (2010) cAMP mediators of pulsatile insulin secretion from glucose-stimulated single beta-cells. J Biol Chem 285:23007-23018

21. Kim JW, Roberts CD, Berg SA, Caicedo A, Roper SD, Chaudhari N (2008) Imaging cyclic AMP changes in pancreatic islets of transgenic reporter mice. PLoS One 3:e2127

22. Zhang J, Ma Y, Taylor SS, Tsien RY (2001) Genetically encoded reporters of protein kinase A activity reveal impact of substrate tethering. Proc Natl Acad Sci U S A 98:14997-15002

23. Lou XL, Yu X, Chen XK et al (2003) Na+ channel inactivation: a comparative study between pancreatic islet beta-cells and adrenal chromaffin cells in rat. J Physiol 548:191-202

24. Zhang C, Zhou Z (2002) Ca(2+)-independent but voltage-dependent secretion in mammalian dorsal root ganglion neurons. Nat Neurosci 5:425-430

25. Dou HQ, Xu YF, Sun JP et al (2012) Thiopental-induced insulin secretion via activation of IP3-sensitive calcium stores in rat pancreatic beta-cells. Am J Physiol Cell Physiol 302:C796-C803

26. Rorsman P (1997) The pancreatic beta-cell as a fuel sensor: an electrophysiologist's viewpoint. Diabetologia 40:487-495

27. Willoughby D, Cooper DM (2007) Organization and Ca2+ regulation of adenylyl cyclases in cAMP microdomains. Physiol Rev 87: 965-1010

28. Roger B, Papin J, Vacher P et al (2011) Adenylyl cyclase 8 is central to glucagon-like peptide 1 signalling and effects of chronically elevated glucose in rat and human pancreatic beta cells. Diabetologia 54: 390-402

29. Merrins MJ, Stuenkel EL (2008) Kinetics of Rab27a-dependent actions on vesicle docking and priming in pancreatic betacells. J Physiol 586:5367-5381

30. Zhang X, Candas M, Griko NB, Taussig R, Bulla LA Jr (2006) A mechanism of cell death involving an adenylyl cyclase/PKA signaling pathway is induced by the Cryl Ab toxin of Bacillus thuringiensis. Proc Natl Acad Sci U S A 103:9897-9902

31. Katz B (1969) The release of neural transmitter substances. Liverpool University Press, Liverpool 
32. Neher E, Sakaba T (2008) Multiple roles of calcium ions in the regulation of neurotransmitter release. Neuron 59:861-872

33. Sudhof TC (2004) The synaptic vesicle cycle. Annu Rev Neurosci 27:509-547

34. Ammala C, Ashcroft FM, Rorsman P (1993) Calcium-independent potentiation of insulin release by cyclic AMP in single beta-cells. Nature 363:356-358

35. Gustavsson N, Lao Y, Maximov A et al (2008) Impaired insulin secretion and glucose intolerance in synaptotagmin-7 null mutant mice. Proc Natl Acad Sci U S A 105:3992-3997

36. Michael DJ, Ritzel RA, Haataja L, Chow RH (2006) Pancreatic betacells secrete insulin in fast- and slow-release forms. Diabetes 55:600 607

37. von Ruden L, Neher E (1993) A Ca-dependent early step in the release of catecholamines from adrenal chromaffin cells. Science 262:1061-1065

38. Zhang B, Sun L, Yang YM et al (2011) Action potential bursts enhance transmitter release at a giant central synapse. J Physiol 589:2213-2227
39. Everett KL, Cooper DM (2013) An improved targeted cAMP sensor to study the regulation of adenylyl cyclase 8 by $\mathrm{Ca} 2+$ entry through voltage-gated channels. PLoS One 8:e75942

40. Tian G, Sandler S, Gylfe E, Tengholm A (2011) Glucose- and hormone-induced cAMP oscillations in alpha- and beta-cells within intact pancreatic islets. Diabetes 60:1535-1543

41. Willoughby D, Masada N, Wachten S et al (2010) AKAP79/150 interacts with $\mathrm{AC} 8$ and regulates $\mathrm{Ca} 2+-$ dependent cAMP synthesis in pancreatic and neuronal systems. J Biol Chem 285:20328-20342

42. Leech CA, Castonguay MA, Habener JF (1999) Expression of adenylyl cyclase subtypes in pancreatic beta-cells. Biochem Biophys Res Commun 254:703-706

43. Fonseca SG, Urano F, Weir GC, Gromada J, Burcin M (2012) Wolfram syndrome 1 and adenylyl cyclase 8 interact at the plasma membrane to regulate insulin production and secretion. Nat Cell Biol 14:1105-1112

44. Takahashi N, Kishimoto T, Nemoto T, Kadowaki T, Kasai H (2002) Fusion pore dynamics and insulin granule exocytosis in the pancreatic islet. Science 297:1349-1352 